\title{
ANALYTICAL INVESTIGATION OF SEISMIC PERFORMANCE OF MASONRY WALLS STRENGTHENED WITH STRAIN HARDENING FIBER REINFORCED GEOPOLYMER MATRIX
}

\author{
ELNARA SATEKENOVA ${ }^{1}$, DICHUAN ZHANG ${ }^{1}$, JONG KIM ${ }^{1} \&$ KAI TAI WAN ${ }^{2}$ \\ ${ }^{1}$ Department of Civil Engineering, School of Engineering, Nazarbayev University, Kazakhstan \\ ${ }^{2}$ Department of Civil and Environmental Engineering, Brunel University London, UK
}

\begin{abstract}
Strain hardening fiber reinforced geopolymer matrix, termed here as strain hardening material, is being proposed as a new seismic retrofitting material. Seismic behavior of the masonry walls with and without the strain hardening material was evaluated through finite element simulations in this paper. The finite element simulation was conducted on a masonry wall model with smeared crack material properties. The effectiveness of the strain hardening material for enhancing the seismic capacity of the masonry wall was evaluated through pushover analyses. Several parameters are considered in the pushover analysis including thickness and mechanical properties of the strain hardening material, wall geometries and loading directions. The force-displacement response obtained from the pushover analysis was used to develop a simplified multi-degree spring model. Nonlinear dynamic time history analyses were conducted using the spring model to evaluate the seismic demand of masonry structures strengthened with the strain hardening material. From the simulation results, it has been found that the strain hardening material can significantly improve the strength and ductility of the masonry wall under earthquakes. Design recommendations are made for retrofitting masonry structures using the proposed strain hardening material.
\end{abstract}

Keywords: seismic retrofitting, masonry wall, strain hardening geopolymer matrix, seismic analysis.

\section{INTRODUCTION}

Masonry comprises a majority of the global built environment. The safety assessment of masonry structures in seismic regions has gained significant attention in recent years because of their low resistance under seismic loads. Unreinforced masonry walls have low capacity to resist tensile stresses and lateral loads from earthquakes, and during earthquakes low capacity results in crack formations, element failures and structural collapses. One of the recent examples is 2003 San Simeon Earthquake $M_{\mathrm{s}} 6.5$ happened in Paso Robles, Central California after which from 53 unreinforced brick buildings, none of 9 retrofitted experienced considerable damages whereas others were extensively damaged and subsequently demolished [1]. The earthquake killed two people, and both of deaths were due to collapse of an unreinforced masonry building. Four days later, Bam Earthquake $\mathrm{M}_{\mathrm{s}} 6.6$ hit Iran killing 26,000 , injuring 30,000 and leaving 75,000 homeless [2]. The consequences of the earthquake were exacerbated by the use of masonry as a major building material which resulted in destroy or damage of about ninety percent of infrastructures and buildings in Bam region. The reason why the earthquakes with the same magnitude resulted in such disparity is the high amount of masonry buildings and absence of reinforcement and retrofitting in them in Bam area.

In addition to low tensile strength, many factors affect seismic behaviour of masonry structures. Neglecting the requirements about the maximum void ratio and compressive strength of bricks, variation in shapes, improper mortar mix design, bad quality of its components lead to inadequate brick units, poor mortar and irregularities in plane and vertical 
directions [3]. When an earthquake happens, this results in the disintegration of masonry and loss of support to floors causing collapse of the structure. Therefore, since unretrofitted or unreinforced masonry structures are prone to serious damages in seismic conditions, it is crucial to develop methods for enhancement of existing buildings. There are a number of approaches for seismic retrofit of masonry structures such as using innovative ductile materials, fiber wrapping, energy-dissipation devices, and adding reinforcement elements [4]. The focus of this study is the improvement of masonry structures by retrofitting bearing walls with a new strain hardening material - Strain Hardening Fiber Reinforced Geopolymer Matrix (SHGM).

The SHGM is an innovative material meeting both strength and sustainability parameters. Geopolymer is synthesised from alkaline activation of aluminosilicate waste materials such as metakaolin, fly ash, rice husk ash, ground granulated blast slag and silica fume [5]. As a result, production of the strain hardening material emits $80 \%$ less carbon dioxide and consumes $60 \%$ less embodied energy in comparison to production of Portland cement, meaning that the material has a good potential to become a key element in the development of sustainable infrastructures [6]. The mechanical properties of fiber reinforced composites depend on various parameters including fibers' strength, Poisson's ratio, aspect ratio, and shape; mortar's strength, stiffness, and shrinkage; and bond properties such as friction and physio-chemical interaction at the interface [5]. In comparison to cementitious matrices, there are a small number of studies on geopolymer composites although it is a growing area of research. Bhutta et al. [7] investigated flexural performance of geopolymer composites with steel and polypropylene macro fibers, and results showed that the material with macro fibers and heat curing has significantly improved compressive strength, flexural toughness and splitting tensile strength. Bernal et al. [8] examined an alkali-activated slag composite reinforced with steel fibers for properties such as compressive, flexural and splitting tensile strengths, pull-out and water absorption properties, and flexural notch sensitivity. The results showed the enormous potential of the material as construction material with and without reinforcement. Sustainability and enhanced mechanical properties of the fiber reinforced geopolymer strain hardening composite make it a promising material for seismic retrofitting of masonry structures.

Although material properties of the fiber reinforced geopolymer strain hardening composite has been examined, little research has been undertaken to study performance of the material at structural level. Therefore, the effect of retrofitting with the material on seismic performance of masonry wall is still undetermined. Consequently, the aim of the research is to conduct analytical investigation of seismic behavior of the masonry wall strengthened with strain hardening fiber reinforced cementitious matrix.

\section{MODEL DEVELOPMENT AND STUDY DESCRIPTION}

In order to conduct analytical investigation of seismic behaviour of masonry wall with and without strain hardening material, nonlinear pushover and dynamic analyses are performed. For this reason, two separate models are developed on finite element analysis tool. Masonry wall model for pushover analysis are made of 3D solid elements and horizontal force are applied incrementally. Obtained results from the pushover analysis in the form of forcedisplacement curves are used as input properties for the development of dynamic analysis model.

For the pushover analysis, 3D model of masonry wall is built in the finite element software. Two different models are considered including model of masonry wall only and model with the strain hardening material at both sides of the wall surface. Masonry wall is modeled as 3D solid elements with unreinforced smeared crack material models, while the 
strain hardening material is modeled as elements with reinforced material model (Fig. 1). The model has a fixed boundary condition at the base, and the interface between the material and masonry is assumed to be rigid and continuous. Uniformly distributed load is applied at the top of the wall to mimic the gravity loads. The pushover analyses are performed by applying increasing displacement at the top in the in-plane and out-of-plane directions.

The model is developed using smeared concept, and properties of masonry are obtained from experimental study conducted by Ganz and Thürlimann [9]. Table 1 shows the mechanical properties used as input parameters for the masonry wall model. The wall model is calibrated to the experimental test for the in-plane behavior of the masonry wall [10], and the results comparison between the pushover curves is shown in Fig. 2(a). As seen, the analytical result reasonably matches the experimental results.

The strain hardening material is modeled as reinforced smeared crack elements. The properties are obtained from the tests conducted by Nematollahi et al. [11] and Zhu et al. [12], and summarized in Table 2. The properties of the reinforcement including tensile stressstrain inputs and volumetric ratio are calibrated to correspond to the results of the direct tensile tests. The stress-strain comparison between the model and the test is shown in Fig. 2(b).

For dynamic analysis, the simplified multi-degree models are constructed. Each floor is modelled as rigid mass and walls are modelled as spring elements (Fig. 3). Material properties of elements are inputted using data from the force-displacement curves obtained in pushover analyses. The model is subjected to ground acceleration in time-history analysis.

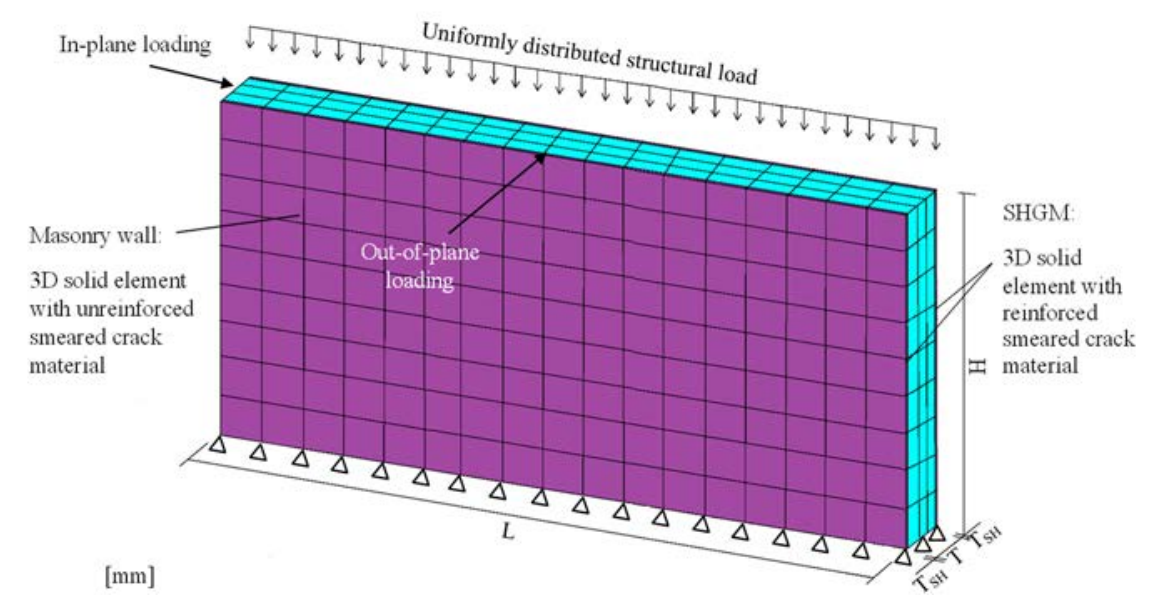

Figure 1: 3D model for pushover analysis. (Source: Modified from Zhu et al., 2018.)

Table 1: Properties of the masonry wall.

\begin{tabular}{|c|c|c|c|}
\hline $\begin{array}{c}\text { Young's } \\
\text { modulus, } \\
\mathrm{MPa}\end{array}$ & $\begin{array}{c}\text { Poisson's } \\
\text { ratio }\end{array}$ & $\begin{array}{c}\text { Uniaxial } \\
\text { crushing } \\
\text { stress, MPa }\end{array}$ & $\begin{array}{c}\text { Uniaxial } \\
\text { cracking } \\
\text { stress, MPa }\end{array}$ \\
\hline 2460 & 0.18 & 7.61 & 0.28 \\
\hline
\end{tabular}


(a)

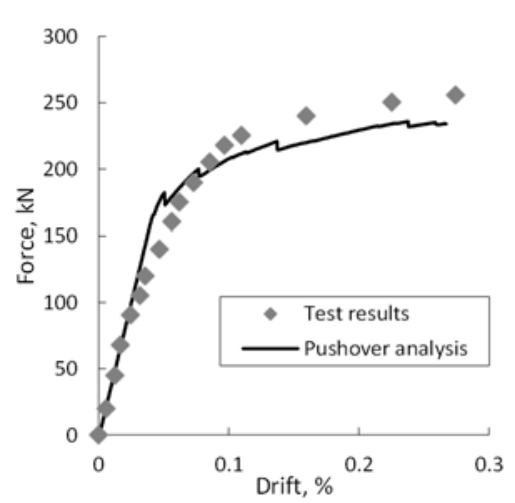

(b)

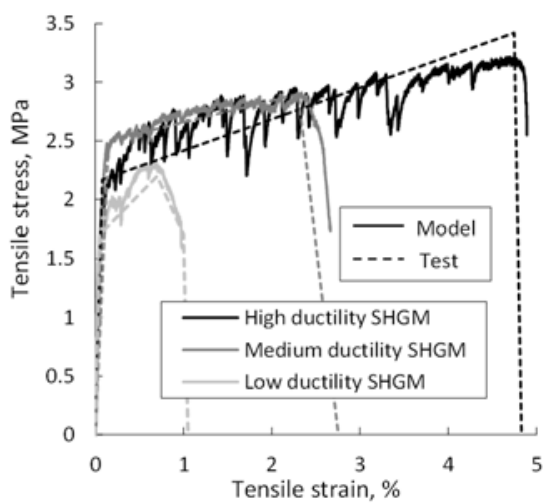

Figure 2: Model validation. (a) Masonry model; (b) Strain hardening material model. (Source: After Zhu et al. 2018.)

Table 2: Properties of the SHGM.

\begin{tabular}{|l|c|c|c|c|c|c|}
\hline \multirow{2}{*}{ Ductility } & \multicolumn{2}{|c|}{$\begin{array}{c}\text { Properties of } \\
\text { reinforcement }\end{array}$} & \multicolumn{2}{|c|}{ Properties of smeared crack model } & \\
\cline { 2 - 6 } & $\begin{array}{c}1^{\text {st }} \\
\text { cracking } \\
\text { strength, } \\
\mathrm{MPa}\end{array}$ & $\begin{array}{c}\text { Peak } \\
\text { tensile } \\
\text { strength, } \\
\mathrm{MPa}\end{array}$ & $\begin{array}{c}\text { Young's } \\
\text { modulus, } \\
\mathrm{MPa}\end{array}$ & $\begin{array}{c}\text { Compressive } \\
\text { strength, } \\
\mathrm{MPa}\end{array}$ & $\begin{array}{c}\text { Tensile } \\
\text { strength, } \\
\mathrm{MPa}\end{array}$ & $\begin{array}{c}\text { Ultimate } \\
\text { strain, \% }\end{array}$ \\
\hline High & 2.17 & 3.42 & 8500 & 23.22 & 0.713 & 4.75 \\
\hline Medium & 2.50 & 2.90 & 8500 & 13.62 & 0.713 & 2.30 \\
\hline Low & 1.70 & 2.20 & 8500 & 23.22 & 0.713 & 0.70 \\
\hline
\end{tabular}

Floor:

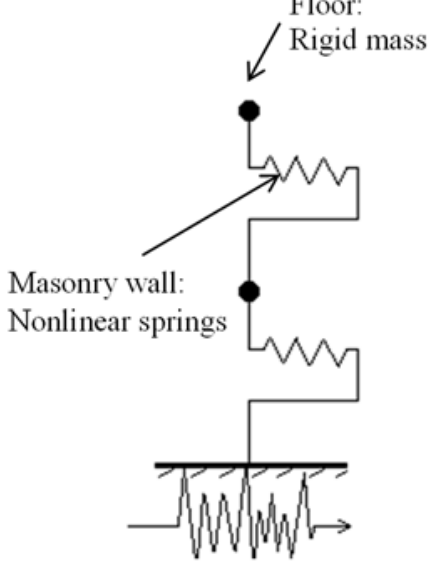

Ground acceleration

Figure 3: Model for dynamic analysis. 
The geometry of the wall is obtained from a prototype structure. The structure is two-story unreinforced masonry building constructed in 1980s and located in Almaty region, Kazakhstan which is known for its high seismicity. The wall chosen for the analysis has dimensions of $6000 \times 3000 \times 230 \mathrm{~mm}$, and its tributary area is $30 \mathrm{~m}^{2}$. It was assumed that the walls are subjected to $10 \mathrm{kPa}$ dead load, and $1.92 \mathrm{kPa}$ live load.

The masonry wall model was subjected to monotonically increasing lateral loads to determine the force-displacement characteristics. The effect of a number of parameters such as SHGM layer thickness, geometry of the wall, mechanical properties of the SHGM, lamination techniques and loading directions on the structural response of the retrofitted wall is investigated through the pushover analysis. The force-displacement curves are used to build the models for the dynamic time-history analyses at two different earthquake levels with 475-years and 2475-years returning periods. Based on the findings, design recommendations for strengthening the masonry wall with the SHGM are made.

\section{RESULTS AND DISCUSSION}

The pushover analysis was conducted by applying $15 \mathrm{~mm}$ incremental displacement to the nodes at the top of the wall model. The effect of the thickness of the strain hardening material is illustrated in Fig. 4(a) in the form of "base shear vs. drift at the top of the wall" curve, where drift is the ratio of the displacement of the wall to the wall's height. First crack in masonry and crushing in masonry and SHGM elements are indicated as markers. As seen, the presence of the strain hardening material layer significantly increased the strength and ductility of the wall. The strength of the wall increases with increase of the SHGM layer thickness. Namely, the $10 \mathrm{~mm}$ SHGM layer made the wall achieve $78 \%$ higher strength than the bare wall, the $15 \mathrm{~mm}$ SHGM layer $-105 \%$, and the $20 \mathrm{~mm}$ SHGM layer $-140 \%$. Also, the ductility increase due to application of the $10 \mathrm{~mm}$ SHGM layer is $66 \%$, the $15 \mathrm{~mm}$ SHGM layer $-41 \%$, and the $20 \mathrm{~mm}$ SHGM layer $-34 \%$. In contrast to the strength, the increase in thickness of the SHGM led to the reduction of the ductility. The possible reason is that the thicker layer of the SHGM provides the higher confinement of masonry. In addition, it can be noticed that the drift at which the first crack in masonry occurred almost does not change significantly with addition of strain hardening material due to the strain compatibility. In the models with 15 and $20 \mathrm{~mm}$ SHGM layer, crushing of masonry observed, but since only one masonry element crushed in both cases, it does not affect further behavior of the models.

Fig. 4(b) shows the bond stress between the SHGM and masonry. It can be seen that the maximum bond stress reached is about $0.005 \mathrm{MPa}$ which is much smaller than the bond strength $(0.24 \mathrm{MPa})$ estimated from the experiment conducted on similar material [13]. Therefore, the assumption that the interface between SHGM and masonry is rigid and continuous seems reasonable.

To study the effect of wall's geometry, four masonry wall models with different aspect ratios $(0.5,0.6,0.8$ and 1.0$)$ were used. The dimensions of the wall models are given in Table 3. Fig. 5(a) shows the results of the parametric study of the effect of aspect ratio corresponding to $0.15 \%$ drift. As seen, application of the SHGM increased the strength of the wall for approximately same amount for all aspect ratios (from 70 to 140\%). Generally, with increase of aspect ratio, the strength of the wall reduces. For aspect ratios 0.6 and 0.8 , the reason may be the reduction in the wall's length, i.e. surface area. For aspect ratio 1.0, the base shear force of the model has the smallest value. This may be explained by the decrease in the model's stiffness as its height becomes twice larger in comparison to others.

The SHGM materials with three different ductility levels were used for evaluation of the effect of the mechanical properties of the SHGM. Fig. 5(b) shows pushover curves of the 

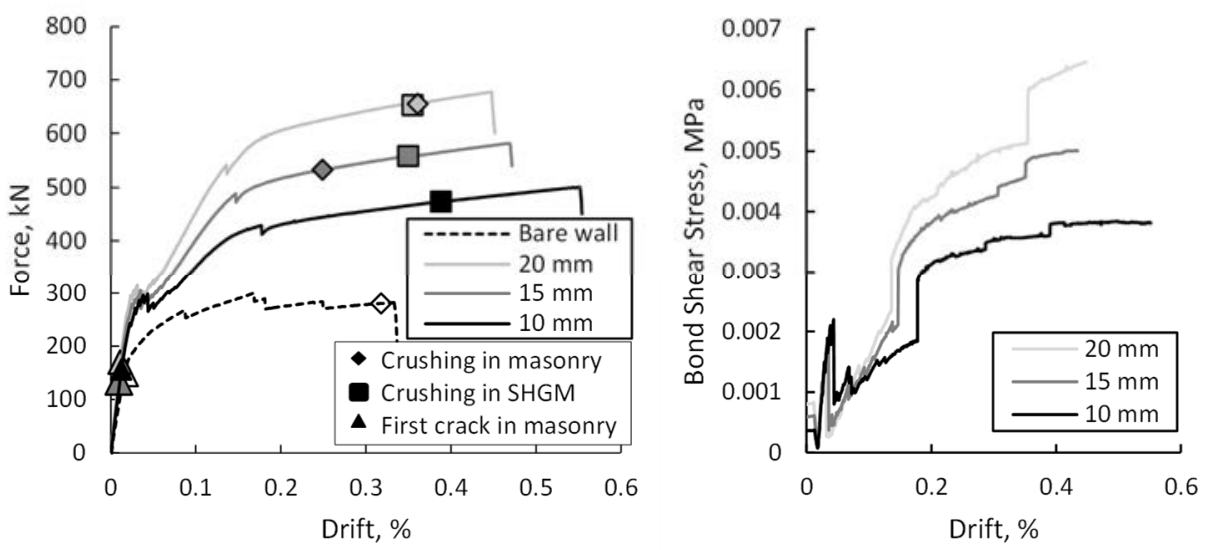

Figure 4: Effect of the SHGM thickness. (a) Pushover curves; (b) Bond stress.

Table 3: Dimensions of the wall models with different aspect ratios.

\begin{tabular}{|c|c|c|c|}
\hline Aspect ratio & $\begin{array}{c}\text { Length of the } \\
\text { wall, } \mathrm{mm}\end{array}$ & $\begin{array}{c}\text { Height of the wall, } \\
\mathrm{mm}\end{array}$ & $\begin{array}{c}\text { Thickness of the } \\
\text { wall, } \mathrm{mm}\end{array}$ \\
\hline 0.5 & 6000 & 3000 & 230 \\
\hline 0.6 & 5000 & 3000 & 230 \\
\hline 0.8 & 3750 & 3750 & 230 \\
\hline 1.0 & 6000 & 6000 & 230 \\
\hline
\end{tabular}

(a)

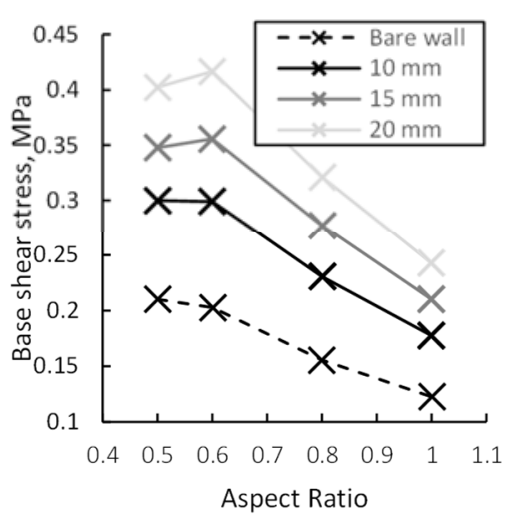

(b)

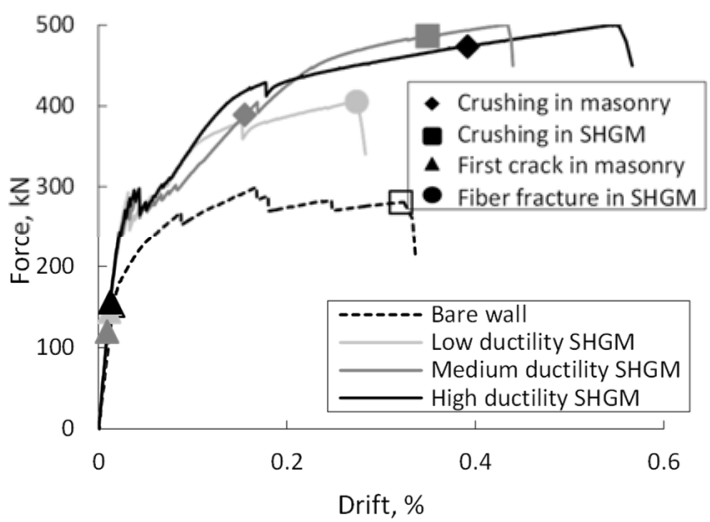

Figure 5: Parametric study. (a) Effect of aspect ratio; (b) SHGM properties. (Source: After Zhu et al., 2018.) 
models with $10 \mathrm{~mm}$ layer of the low, the medium and the high ductility SHGM applied at the both side of the wall. As seen, the strength of the wall increases with increase of ductility of the material (from $44 \%$ to $78 \%$ depending on the ductility of the SHGM). However, the wall with the low ductility SHGM showed $12 \%$ lower ductility than the bare wall, possibly because the failure of the wall with the low ductility SHGM is controlled by the fracture of the fiber. The medium and the high ductility SHGM increase overall ductility of the wall for $34 \%$ and $72 \%$, respectively. Also, as seen in the pushover curve, the masonry element starts to crush earlier in the wall with the medium ductility SHGM than that with the high ductility SHGM. The possible reason is that the medium ductility SHGM is slightly stronger than the high ductility SHGM (Table 2).

The out-of-plane response of the strengthened wall was also examined. In Fig. 6, the responses of the model under in-plane and out-of-plane loading are compared. It can be seen that the presence of the SHGM layer is also effective for the out-of-plane loading. In comparison to in-plane loading, the strengthened wall under out-of-plane loading showed higher strength and ductility increase, possibly because the response of the wall is controlled by flexural deformation in the out-of-plane loading, and by shear deformation in the in-plane loading. Also, since the load is normal to the interface surface in the out-of-plane loading case, the model undergoes much higher bonding stress than in the in-plane loading. However, it should be noticed that even if the bond stress in out-of-plane loading is about four times larger than in in-plane loading, it is still considerably less than the bonding strength of the material $(0.24 \mathrm{MPa})[13]$.

In addition, the masonry wall with aspect ratio 1.0 was analysed to evaluate the effects of the one-side and diagonal strengthening techniques. Results of pushover analysis for oneside lamination are presented in Fig. 7(a), where it is compared to two-side lamination results. It can be stated that one-side lamination increases the strength of the wall (from $32 \%$ to $67 \%$ ), but less effective in comparison to strengthening of both sides. Also, the one-side lamination of the wall with the $20 \mathrm{~mm}$ SHGM layer resulted in similar pushover curve as for two-side lamination with the $10 \mathrm{~mm}$ SHGM layer. The ductility enhancement is about the same for the one-side and two-side lamination. The effect of diagonal lamination technique was examined on the wall with aspect ratio 0.5 and the $10 \mathrm{~mm}$ SHGM layer applied at the both side of the model. Usually, the cracks on the wall under horizontal loading are generated

(a)

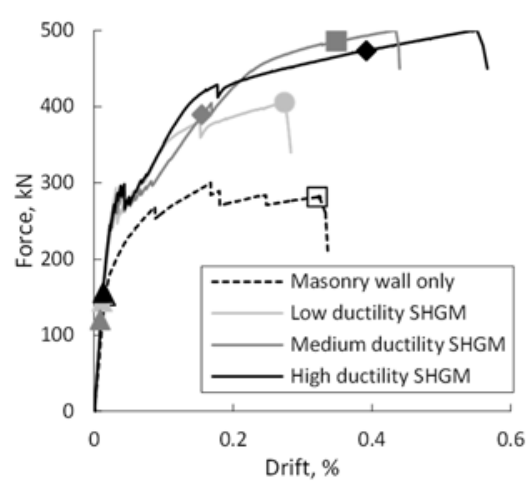

(b)

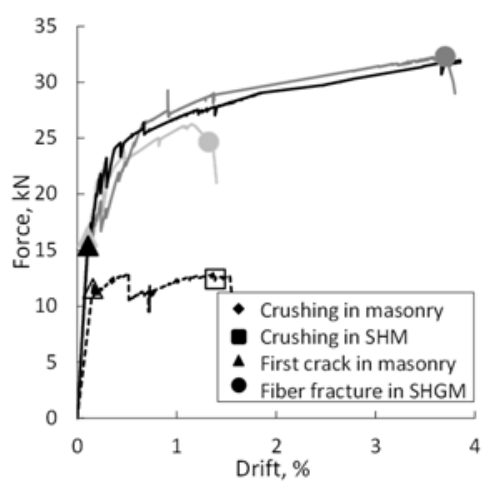

Figure 6: Pushover curves for different loading cases. (a) In-plane; (b) Out-of-plane. (Source: After Zhu et al., 2018.) 
(a)

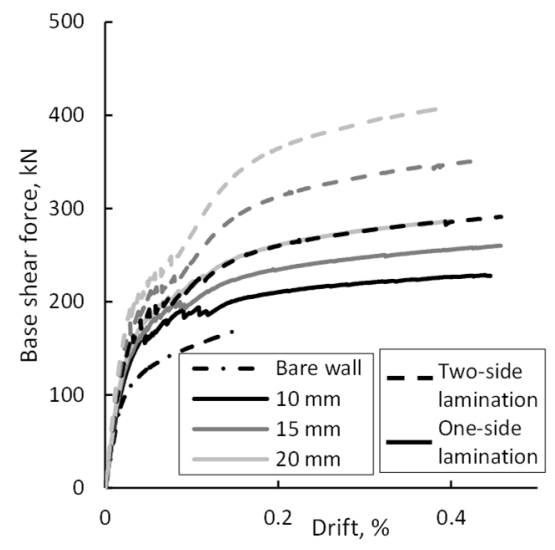

(b)

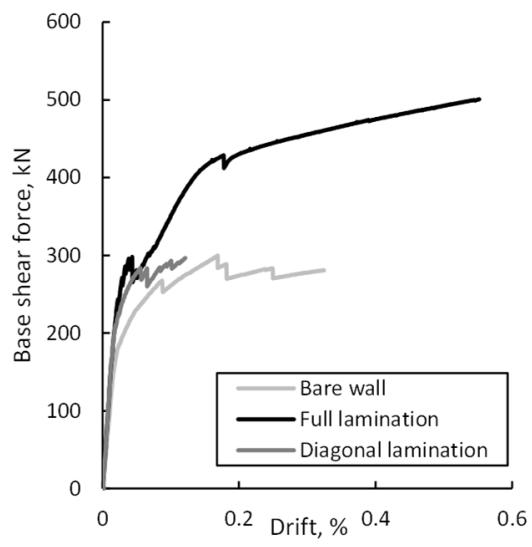

Figure 7: Effect of different lamination techniques. (a) One-side; (b) Diagonal.

along the diagonal of the wall; therefore, the SHGM was applied forming the X shape. The pushover curve for diagonal lamination is given in Fig. 7(b) and compared to the full lamination. As seen, the diagonal lamination insignificantly increases the strength of the wall (only for $8 \%$ ), and even decreases the ductility for considerable amount meaning that the diagonal application of the wall may not be effective for strengthening the masonry. The possible reason is that the triangle sections of the wall which are left vulnerable during diagonal lamination have significant influence on the overall behavior of the wall as well as diagonal regions.

In order to test the structural model under ground motion records, nonlinear dynamic analysis was conducted at two earthquake levels with 475-years and 2475-years returning periods. The dynamic analysis requires ground motion records, which are characterized by earthquake response spectrum concept. The design response spectrum of Almaty was developed, and ten ground motion histories that have sufficiently similar ground motion characteristics were selected (Fig. 8). The detailed information about selected ground motions such as location, magnitude, date, peak ground acceleration (PGA) and scaling factor can be found in Table 4.

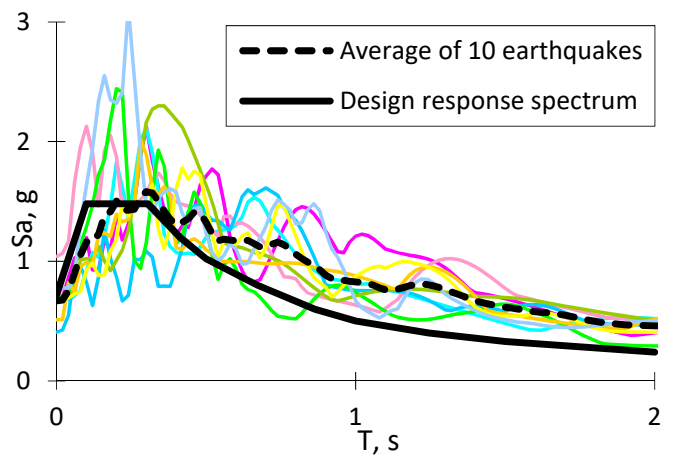

Figure 8: Design response spectrum and selected ground motions. 
Table 4: Ground motion characteristics.

\begin{tabular}{|c|l|c|c|c|}
\hline$\#$ & Earthquake & Magnitude & Date & PGA, g \\
\hline EQ01 & Chi Chi & 7.6 & 20.09 .1999 & 0.53 \\
\hline EQ02 & Chi Chi & 7.6 & 20.09 .1999 & 0.69 \\
\hline EQ03 & Erzincan, Turkey & 6.7 & 13.03 .1992 & 0.68 \\
\hline EQ04 & Imperial Valley & 6.5 & 15.10 .1979 & 1.04 \\
\hline EQ05 & Loma Prieta & 7.0 & 17.10 .1989 & 0.41 \\
\hline EQ06 & Loma Prieta & 7.0 & 17.10 .1989 & 0.69 \\
\hline EQ07 & Northridge & 6.7 & 17.01 .1994 & 0.69 \\
\hline EQ08 & Northridge & 6.7 & 17.01 .1994 & 0.50 \\
\hline EQ09 & Superstition Hills & 6.7 & 24.11 .1987 & 0.67 \\
\hline EQ10 & Tabas, Iran & 7.4 & 16.09 .1978 & 0.78 \\
\hline
\end{tabular}

One- to five-story masonry wall models with the $10 \mathrm{~mm}, 15 \mathrm{~mm}$ and $20 \mathrm{~mm}$ SHGM layers were subjected to ten selected ground motions with 475-years and 2475-years returning periods, and the displacement values of each floor were obtained and averaged. Fig. 9(a) shows the maximum experienced inter-story drifts of the wall models subjected to earthquakes with returning period of 475 years for different number of stories, N. As seen, bare wall experiences about three times more displacement than the strengthened walls. For example, considering the four-story structure, the first floor of the bare wall structure experienced approximately $1.27 \%$ inter-story drift, whereas the strengthened wall with the $15 \mathrm{~mm}$ SHGM experienced approximately $0.47 \%$ drift. Fig. 9(b) shows how the maximum experienced inter-story drift normalized by the drift capacity changes with the story number. The drift capacity is defined by the divergence of the model, and the trend line in the figure acts as a boundary which shows the models the drift values of which exceed the capacity. As seen, the application of the SHGM improved the overall seismic behaviour of the structure. Under the earthquake with returning period of 475 years, the one-, two- and three-story strengthened models did not exceed the drift capacity, whereas only one-story unstrengthened model is in "safe" region. The four- and five-story strengthened structures exceeded the capacity of the building, but their ductility is higher than the ductility of the bare wall for $71 \%$ and $75 \%$, respectively. The results for the strengthened wall models with the 10, 15 and $20 \mathrm{~mm}$ SHGM layer are almost the same.

The same masonry models were analysed under earthquake with returning period of 2475 years. In Fig. 10(a), the results of dynamic analysis for the models are shown. As seen, the strengthening of wall reduced the value of drifts also about three times. For example, for three-story models, the maximum inter-story drift of unstrengthened wall is about $2.18 \%$, whereas the drift of the wall with the $15 \mathrm{~mm}$ SHGM is about $0.69 \%$. Fig. 10 (b) shows the normalized drift values of the strengthened and unstrengthened models. At this earthquake level, the drift values for the one- and two-story masonry wall models with the SHGM is under the trend line, while only the one-story bare masonry wall model is within the drift capacity. The ductility values of the remaining models also significantly increased: the threestory model - for $74 \%$, the four-story model - for $78 \%$, and five-story $-77 \%$. 
(a)

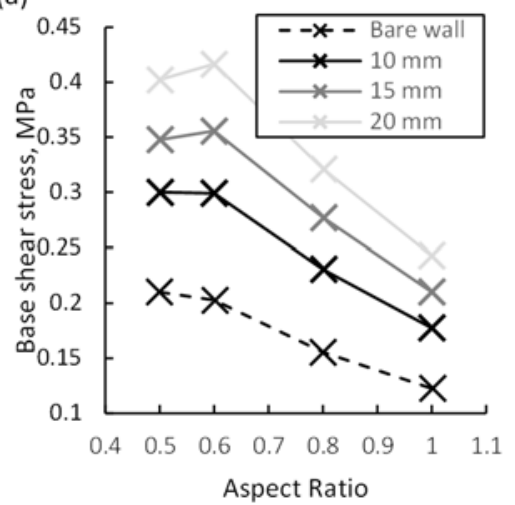

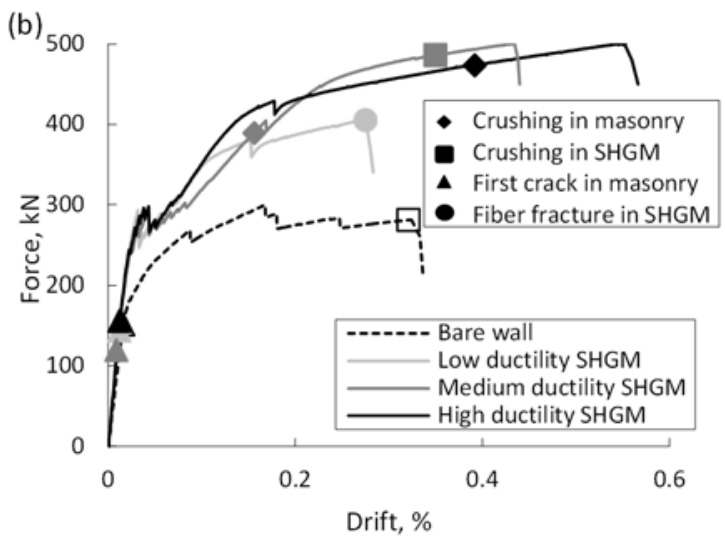

Figure 9: Dynamic analysis results for earthquake with 475 years returning period. (a) Interstory drift; (b) Normalized drift.

(a)

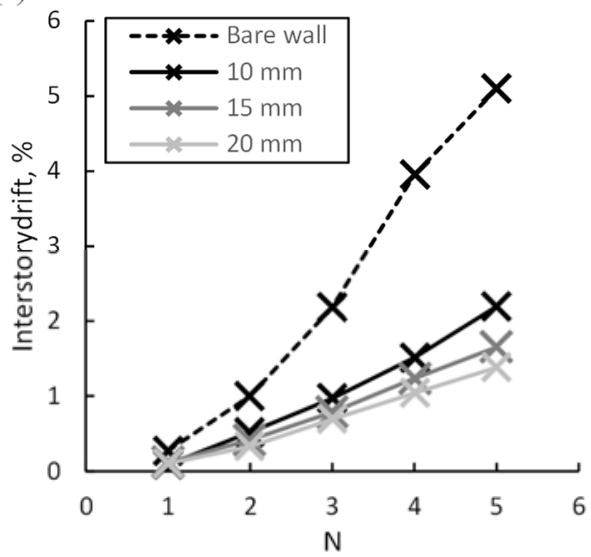

(b)

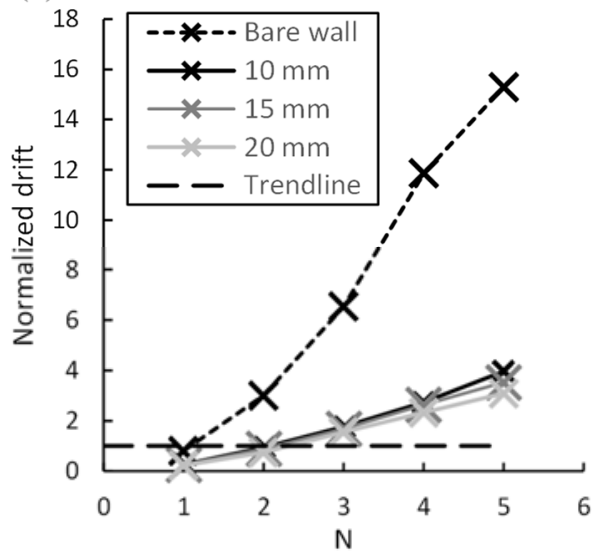

Figure 10: Dynamic analysis results for earthquake with 2475 years returning period. (a) Interstory drift; (b) Normalized drift.

\section{CONCLUSION AND LIMITATIONS}

This study investigated the seismic performance of masonry wall with and without innovative material named SHGM.The pushover analysis results showed that the proposed strengthening technique is a promising approach to improve seismic behavior of the masonry walls. Application of the SHGM to the masonry wall increased its strength and ductility for both in-plane and out-of-plane loading directions. The increase in thickness of the applied SHGM resulted in the increase of the strength of the masonry wall for $78 \%-140 \%$. Also, the increase in thickness of the applied SHGM resulted in the reduction of the ductility of the masonry wall, possibly because of enhancement of the confinement effect. The strengthening effect of the SHGM remained at the same level for the walls with aspect ratios 0.5, 0.6, 0.8 
and 1.0. It was discovered that the effectiveness of the strengthening depends on the ductility of the SHGM. The strengthening with the low ductility SHGM can lead to decrease of the wall's ductility, possibly because the failure of the wall with the low ductility SHGM is controlled by the fracture of the fiber. The strengthening of only one side of the masonry wall also increased its strength, but in comparison to both-side lamination, the one-side lamination is less effective for $10-23 \%$. The influence of the strengthening of one side and both sides of the masonry wall on its ductility is almost the same. The diagonal lamination technique increased the strength of the wall five times less than the full lamination and decreased the wall's ductility.

The dynamic analysis results also showed the positive effect of the strengthening of masonry walls. The application of the SHGM increased the ductility of one- to five-story masonry structure models under earthquakes with returning periods of 475 and 2475 years. The thickness of the SHGM did not significantly influence the performance of the masonry structure models in the dynamic analysis. Only one-story unstrengthened masonry structure model could resist the earthquakes with 475- and 2475-years returning period. In contrast, up to two- and four-story strengthened masonry structure model could withstand the ground motion accelerations of the earthquake with 2475-years and 475-years returning period, respectively.

Based on the findings, the following design recommendations can be made. The SHGM should be applied on the both sides of the wall, and the lamination of the whole surface is preferred rather than the diagonal lamination. The layer thickness of the strain hardening material is recommended to be $10 \mathrm{~mm}$, because, firstly, this is the most cost-effective option; secondly, the wall with the $10 \mathrm{~mm}$ SHGM showed the most ductile response; thirdly, no significant difference between the dynamic responses of 10, 15 and $20 \mathrm{~mm}$ models was found. The technique should be used for strengthening the masonry structures which have up to four floors. More important, the SHGM must have high ductility, because strengthening of the wall with the low ductility material can lead to opposite results.

In addition, there are a few of notable limitations in this research. To begin with, the masonry wall model was developed using the smeared crack model which involves a number of assumptions. Firstly, the masonry which is composed of brick units and mortar joints is smeared out in the continuum, and masonry is treated as homogenous anisotropic elements. Secondly, the cracks are assumed to be smeared over the masonry wall, and they only affect the material behavior from one of isotropic before cracking to orthotropic character after cracking. Third, the smeared crack model does not preserve permanent memory of the damage orientations which limits the usage of the model for cyclic loading conditions. Therefore, the dynamic analysis of this study was conducted using simplified 2D model of the masonry structures. Also, the interface between the masonry wall model and the SHGM layer was assumed to be rigid, and the bonding strength between two materials was not considered. For future research, the correlation of the results with experimental tests is recommended.

\section{ACKNOWLEDGEMENT}

This work was supported by European Commission under grant "GEOHarzards: Risk Assessment, Mitigation and Prevention (GEO-RAMP)" (H2020-MSCA-RISE-2014). Any opinions, findings, and conclusions or recommendations expressed in this material are those of the author and do not necessarily reflect the views of European Commission. 


\section{REFERENCES}

[1] Federal Emergency Management Agency (FEMA). Unreinforced Masonry Buildings and Earthquakes: Developing Successful Risk Reduction Programs, P-774, Online. www.fema.gov/media-library-data/20130726-1728-25045-2959/femap774.pdf. Accessed on: 10 Feb. 2018.

[2] Rogers, C.W., Bam Earthquake, Research Starters, Salem Press Encyclopaedia, p.4, 2013.

[3] Dogangun, A., Ural, A. \& Livaoglu, R., Seismic perofrmance of masonry buildings during recent earthquakes in Turkey. Presented at $14^{\text {th }}$ World Conference on Earthquake Engineering, Beijing, China, 2008.

[4] Garofano, A., Ceroni, F. \& Pecce, M., Modelling of the in-plane behaviour of masonry walls strengthened with polymeric grids embedded in cementitious mortar layers. Composites Part B, 85, pp. 243-258, 2016.

[5] Al-Majidi, M., Lampropoulos, A. \& Cundy, A., Tensile properties of a novel fiber reinforced geopolymer composite with enhanced strain hardening characteristics. Composite Structures, 168, pp. 402-427, 2017.

[6] Duxson, P., Provis, J.L., Lukey, G.C. \& Van Deventer, J.S., The role of inorganic polymer technology in the development of "Green Concrete". Cem Concr Res, 37(12), pp. 1590-1597, 2007.

[7] Bhutta, A., Borges, P.H., Zanotti, C., Farooq, M. \& Banthia, N., Flexural behavior of geopolymer composites reinforced with steel and polypropylene macro fibers. Cement and Concrete Composites, 80, pp. 31-40, 2017.

[8] Bernal, S., De Gutierrez, R., Delvasto, S. \& Rodriguez, E., Performance of an alkaliactivated slag concrete reinforced with steel fibers. Construction and Building Materials, 24(2), pp. 208-214, 2010.

[9] Ganz, H.R. \& Thürlimann, B., Tests on the biaxial strength of masonry. Report No. 7502-3, Institute of Structural Engineering, ETH Zurich, Zurich, Switzerland, 1982.

[10] Ganz, H.R. \& Thürlimann, B., Tests on masonry walls under normal and shear loading. Report No. 7502-4, Institute of Structural Engineering, ETH Zurich, Zurich, Switzerland, 1984.

[11] Nematollahi, B., Sanjayan, J. \& Shaikh, F.U.A., Matrix design of strain hardening fiber reinforced engineered geopolymer composite. Composites Part B: Engineering, 89, pp. 253-265, 2015.

[12] Zhu, H., Wan, K.T, Satekenova, E., Zhang, D., Leung, C.K.Y. \& Kim, J., Development of lightweight strain hardening cementitious composite for structural retrofit and energy efficiency improvement of unreinforced masonry housings. Construction and Building Materials, 167, pp. 791-812, 2018.

[13] Olivito, R.S., Codispoti, R. \& Cevallos, O.A., Bond behavior of Flax-FCRM and PBOFRCM composites applied on clay bricks: Experimental and theoretical study. Composite Structures, 146, pp. 221-231, 2016. 